\title{
To track or not to track: wheeze phenotypes in preschool children
}

\author{
To the Editor:
}

We applaud the robust statistical approach used by SPYCHER et al. [1] to assess the temporal stability of episodic viral wheeze (EVW) and multitrigger wheeze (MTW) phenotypes in young children. They reported that in two large population-based cohort studies, children who continued to wheeze at 4 and 6 years of age showed a tendency to maintain the same phenotype from the age of 2 years. The authors' conclusion, and that of the accompanying editorial, is that the EVW and MTW phenotypes in young children are stable and track over time [2], and that these phenotypes may represent different disease entities $[1,2]$. We would like to call for caution in interpreting these results because they are based on statistical probability, not on clinical differential diagnosis.

The statistical analysis that the authors have used examines whether crossover between phenotypes is due to chance or whether there is any tendency to track. If the phenotype at follow-up had nothing to do with the phenotype at baseline (except for its severity, which was adjusted for because it is known that severe wheeze tends to persist), then phenotype distribution at follow-up would not differ from chance, with each phenotype appearing with a probability equal to its prevalence. The data of SpYcher et al. [1] showed that this was not the case: the odds ratios of remaining in the EVW and MTW phenotypes between the ages of 2 and 4 years were 4.9-9.4 and 12.9-20.5, respectively [1]. Whilst this convincingly shows that the likelihood of phenotype persistence is larger than one would expect based on chance alone, it does not rule out or contradict phenotype switching over time, which has been described previously [3, 4].

First, the authors show that the majority of preschool-aged children with EVW and MTW will not have either EVW or MTW 2 years later as they will have become asymptomatic over time. This is in agreement with earlier population studies [5]. Second, figure 1 in the paper article by SPYCHER et al. [1] shows that $\sim 10 \%$ of the 2-year-olds with MTW cross over to EVW and $\sim 20 \%$ of the 2-year-olds with EVW cross over to MTW by the age of 4 years. These crossover proportions are lower than those in our original publication on the topic in 2010, in which we followed up preschool children treated in hospital-based paediatric practice with inhaled corticosteroids (ICS) for 1 year [3]. It appears, therefore, that phenotype changes in preschool children with recurrent wheeze do occur, and that such changes are more common in children treated with ICS for wheezing in primary and secondary care $[3,4]$ than they are at general population level [1].

Although the results of SPYCHER et al. [1] suggest that the pathophysiology of EVW and MTW may differ [1], we believe their findings should not yet lead to a different approach in the treatment of preschool wheeze. There is consensus among clinicians and researchers that the severity and frequency of wheeze symptoms determine the need for daily controller therapy in preschool children with recurrent wheezing [6]. There is convincing evidence from a large number of valid randomised controlled trials that ICS reduce the frequency and severity of wheeze episodes in preschool children with recurrent wheeze, independent of wheeze phenotype [7]. Adherence to ICS is the single most important determinant of asthma control in preschool children with recurrent wheeze [8]. By contrast, montelukast has not been shown to be effective in reducing wheeze episodes in preschool children with recurrent wheezing [9].

The relatively high remission rate in preschool children with EVW in the general population cohort of SPYcher et al. [1] should not lead to therapeutic nihilism in patients with this condition. The likelihood of long-term remission is considerably lower in patients referred to hospital-based paediatric practice because of more severe symptoms [10]. These patients do have troublesome symptomatic wheezing that responds to daily controller therapy $[7,8]$.

@ERSpublications

Wheeze phenotypes in preschool children are insufficiently stable and valid to base treatment decisions upon http://ow.ly/HFhd30ivJyq

Cite this article as: Brand PLP, Schultz A. To track or not to track: wheeze phenotypes in preschool children. Eur Respir J 2018; 51: 1800042 [https://doi.org/10.1183/13993003.00042-2018]. 
In conclusion, whilst the landmark study by SPYCHER et al. [1] shows a statistical likelihood larger than chance of phenotype persistence in preschool children with recurrent wheezing, a considerable minority of children with a given phenotype at the age of 2 years will switch to another phenotype at the age of 4 years if they remain symptomatic, and the majority will not remain symptomatic. As the accompanying editorial states, the overall prognostic value of the EVW-MTV classification is low [2]. As much as we would love to be able to predict which preschool wheezers become "true asthmatics" by the age of 6 years, the EVW-MTW phenotype distinction does not allow this, and it should therefore not be used as a basis for decisions on long-term daily controller therapy in these patients. The frequency and severity of wheeze symptoms in preschool children should remain the key considerations in the decision to prescribe daily preventer therapy in preschool children with recurrent troublesome wheezing [6], and ICS remain the preferred treatment option in preschool children with wheeze of sufficient severity to warrant such daily controller therapy, irrespective of wheeze phenotype [6, 7].

Paul L.P. Brand ${ }^{1,2}$ and André Schultz ${ }^{3,4}$

${ }^{1}$ Isala Women and Children's Hospital, Zwolle, the Netherlands. ${ }^{2}$ UMCG Postgraduate School of Medicine, University Medical Centre and University of Groningen, Groningen, The Netherlands. ${ }^{3}$ Telethon Kids Institute, University of Western Australia, Perth, Australia. ${ }^{4}$ Dept of Respiratory Medicine, Princess Margaret Hospital for Children, Perth, Australia.

Correspondence: Paul L.P. Brand, Isala Women and Children's Hospital, PO Box 10400, Zwolle, 8000 GK, the Netherlands. E-mail: p.l.p.brand@isala.nl

Received: Jan 072018 | Accepted: Jan 292018

Conflict of interest: None declared.

\section{References}

1 Spycher BD, Cochrane C, Granell R, et al. Temporal stability of multitrigger and episodic viral wheeze in early childhood. Eur Respir J 2017; 50: 1700014.

2 Caudri D. Multi-trigger and viral wheeze: describing symptoms or defining diseases? Eur Respir J 2017; 50: 1701283 .

3 Schultz A, Devadason SG, Savenije OE, et al. The transient value of classifying preschool wheeze into episodic viral wheeze and multiple trigger wheeze. Acta Paediatr 2010; 99: 56-60.

4 van Wonderen KE, Geskus RB, van Aalderen WM, et al. Stability and predictiveness of multiple trigger and episodic viral wheeze in preschoolers. Clin Exp Allergy 2016; 46: 837-847.

5 Savenije OE, Kerkhof M, Koppelman GH, et al. Predicting who will have asthma at school age among preschool children. J Allergy Clin Immunol 2012; 130: 325-331.

6 Brand PL, Caudri D, Eber E, et al. Classification and pharmacological treatment of preschool wheezing: changes since 2008. Eur Respir J. 2014; 43: 1172-1177.

7 Kaiser SV, Huynh T, Bacharier LB, et al. Preventing exacerbations in preschoolers with recurrent wheeze: a meta-analysis. Pediatrics 2016; 137: e20154496.

8 Klok T, Kaptein AA, Duiverman EJ, et al. It's the adherence, stupid (that determines asthma control in preschool children)! Eur Respir J 2014; 43: 783-791.

9 Hussein HR, Gupta A, Broughton S, et al. A meta-analysis of montelukast for recurrent wheeze in preschool children. Eur J Pediatr 2017; 176: 963-969.

10 Kappelle L, Brand PL. Severe episodic viral wheeze in preschool children: high risk of asthma at age 5-10 years. Eur J Pediatr 2012; 171: 947-954. 